University of Wollongong

Research Online

Australian Institute for Innovative Materials -

Papers

Australian Institute for Innovative Materials

$1-1-2013$

\title{
1-3 piezoelectric composites for high-temperature transducer applications
}

Lili Li

The Pennsylvania State University, Xi'an Jiaotong University

Shujun Zhang

Blatek Inc., The Pennsylvania State University, Xi'an Jiaotong University, shujun@uow.edu.au

Zhuo Xu

Xi'an Jiaotong University

Fei Wen

Xi'an Jiaotong University

Xuecang Geng

Blatek, Inc.

See next page for additional authors

Follow this and additional works at: https://ro.uow.edu.au/aiimpapers

Part of the Engineering Commons, and the Physical Sciences and Mathematics Commons

Research Online is the open access institutional repository for the University of Wollongong. For further information contact the UOW Library: research-pubs@uow.edu.au 


\title{
1-3 piezoelectric composites for high-temperature transducer applications
}

\begin{abstract}
High-temperature $\mathrm{Pb}(\mathrm{Zr}, \mathrm{Ti}) 03 /$ epoxy 1-3 composites were fabricated using the dice and fill method. The epoxy filler was modified with glass spheres in order to improve the thermal reliability of the composites at elevated temperatures. Temperature-dependent dielectric and electromechanical properties of the composites were measured after ageing at $250^{\circ} \mathrm{C}$ with different dwelling times. Obvious cracks were observed and the electrodes were damaged in the composite with unmodified epoxy after $200 \mathrm{~h}$, leading to the failure of the composite. In contrast, composites with $>12 \mathrm{vol} \%$ glass sphere loaded epoxies were found to exhibit minimal electrical property variation after ageing for $500 \mathrm{~h}$, with dielectric permittivity, piezoelectric coefficient and electromechanical coupling being on the order of $940,310 \mathrm{pC} \mathrm{N}-1$ and $57 \%$, respectively. This is due to the improved thermal expansion behaviour of the modified filler. 2013 IOP Publishing Ltd.
\end{abstract}

\section{Keywords}

high, composites, applications, piezoelectric, 3, 1, temperature, transducer

Disciplines

Engineering | Physical Sciences and Mathematics

\section{Publication Details}

Li, L., Zhang, S., Xu, Z., Wen, F., Geng, X., Lee, H. Jae. \& Shrout, T. R. (2013). 1-3 piezoelectric composites for high-temperature transducer applications. Journal of Physics D: Applied Physics, 46 (16), 165306-1-165306-6.

\section{Authors}

Lili Li, Shujun Zhang, Zhuo Xu, Fei Wen, Xuecang Geng, Hyeong Jae Lee, and Thomas R. Shrout 
1-3 piezoelectric composites for high-temperature transducer applications

This content has been downloaded from IOPscience. Please scroll down to see the full text. 2013 J. Phys. D: Appl. Phys. 46165306

(http://iopscience.iop.org/0022-3727/46/16/165306)

View the table of contents for this issue, or go to the journal homepage for more

Download details:

IP Address: 130.130.37.84

This content was downloaded on 26/04/2016 at 06:32

Please note that terms and conditions apply. 


\title{
1-3 piezoelectric composites for high-temperature transducer applications
}

\author{
Lili Li ${ }^{1,2}$, Shujun Zhang ${ }^{1,2,4}$, Zhuo Xu ${ }^{1}$, Fei Wen ${ }^{1}$, Xuecang Geng ${ }^{3}$, \\ Hyeong Jae Lee ${ }^{2}$ and Thomas R Shrout ${ }^{2}$ \\ ${ }^{1}$ Electronic Materials Research Laboratory, Key Laboratory of the Ministry of Education \& International \\ Center for Dielectric Research, Xi' an Jiaotong University, Xi' an 710049, People's Republic of China \\ ${ }^{2}$ Materials Research Institute, Pennsylvania State University, University Park, Pennsylvania 16802, USA \\ ${ }^{3}$ Blatek Inc., State College, Pennsylvania 16801, USA \\ E-mail: soz1@psu.edu
}

Received 20 November 2012, in final form 9 February 2013

Published 3 April 2013

Online at stacks.iop.org/JPhysD/46/165306

\begin{abstract}
High-temperature $\mathrm{Pb}(\mathrm{Zr}, \mathrm{Ti}) \mathrm{O}_{3}$ /epoxy 1-3 composites were fabricated using the dice and fill method. The epoxy filler was modified with glass spheres in order to improve the thermal reliability of the composites at elevated temperatures. Temperature-dependent dielectric and electromechanical properties of the composites were measured after ageing at $250{ }^{\circ} \mathrm{C}$ with different dwelling times. Obvious cracks were observed and the electrodes were damaged in the composite with unmodified epoxy after $200 \mathrm{~h}$, leading to the failure of the composite. In contrast, composites with $>12 \mathrm{vol} \%$ glass sphere loaded epoxies were found to exhibit minimal electrical property variation after ageing for $500 \mathrm{~h}$, with dielectric permittivity, piezoelectric coefficient and electromechanical coupling being on the order of $940,310 \mathrm{pC} \mathrm{N}^{-1}$ and $57 \%$, respectively. This is due to the improved thermal expansion behaviour of the modified filler.
\end{abstract}

(Some figures may appear in colour only in the online journal)

\section{Introduction}

High-temperature ultrasonic transducers are widely used in various applications, including high-temperature nondestructive testing (NDT) and well logging for oil, gas and geothermal industries [1-4]. Most of the oil wells' temperature is below $175^{\circ} \mathrm{C}$; however, it is about $200{ }^{\circ} \mathrm{C}$ for high-pressure and high-temperature wells, and further increases to $250^{\circ} \mathrm{C}$ and above for geothermal wells. Thus, high-temperature ultrasonic transducers with operational temperatures $\geqslant 250{ }^{\circ} \mathrm{C}$ are desirable $[5,6]$. Transducers using conventional PZT monolithic ceramics have been fabricated for different ultrasonic applications at elevated temperature; however, they suffer from the low sensitivity, low resolution and poor signalto-noise ratio, associated with the low thickness coupling factors and high acoustic impedance of the ceramics [7].

1-3 piezoelectric composites offer advantages of increased thickness electromechanical coupling factors, reduced lateral vibration mode across the width of the resonator, and tailored acoustic impedance, leading to the

\footnotetext{
4 Author to whom any correspondence should be addressed.
}

improved resolution and bandwidth of transducers [8-11]. In addition, 1-3 composites show improved conformability and a large reduction of thermal stress in the transducers due to the compliancy of the polymer phase $[12,13]$. Previous work on high-temperature 1-3 piezoelectric composites was focused on $\mathrm{LiNbO}_{3}$ /cement and PZT/epoxy structure [14-19]. $\mathrm{LiNbO}_{3} /$ cement composites were reported to be functional above $400{ }^{\circ} \mathrm{C}$; however, the low electromechanical coupling of $\mathrm{LiNbO}_{3}$ single crystal limited their applications. Conventional 1-3 PZT/epoxy composites are limited in the temperature usage range of $<180{ }^{\circ} \mathrm{C}$, due to the relatively low glass transition temperature $\left(T_{\mathrm{g}}\right)$ and high thermal expansion coefficient (TEC) of the polymer fillers. Thus, internal stress induced by the different TEC of ceramics and polymers, may give rise to cracking and debonding in the composites and leads to structural failure. In order to obtain lower TEC in the epoxy, one effective approach is to introduce inorganic filler particles and/or short fibres with low TEC into the epoxy resin matrix, where fused silica (TEC $=0.5 \mathrm{ppm}^{\circ} \mathrm{C}^{-1}$ ) has been widely used as filler [20,21].

In this work, high-temperature 1-3 composites fabricated using high Curie temperature $\left(T_{\mathrm{c}}\right)$ PZT ceramic (TRS203, 
$T_{\mathrm{c}} \sim 380^{\circ} \mathrm{C}$ ) and glass spheres modified epoxy (to reduce the TEC of the epoxy) were studied. Temperaturedependent properties of the composites were investigated; the temperature stability and reliability (high-temperature ageing) were evaluated.

\section{Experimental procedures}

PZT composites were fabricated using the conventional dice and fill method [22]. The piezoelectric ceramics used in this study were commercially available high $T_{\mathrm{c}}$ PZT (TRS203, TRS Technologies Inc.). The temperature-dependent properties of TRS203 were compared with conventional PZT5A (TRS200, TRS Technologies Inc.). For the passive phase, Duralco 4703 polymers (Cotronics Corp.) with various volume ratios of glass spheres $(\sim 0 \%, 4 \%, 12 \%$ and $20 \%)$ were investigated. The kerf and pillar widths were controlled to be $0.27 \mathrm{~mm}$ and $0.81 \mathrm{~mm}$, respectively, with PZT volume fraction being on the order of $56 \%$. The glass sphere modified epoxies were then backfilled into the kerfs and cured at $120^{\circ} \mathrm{C}$ for $4 \mathrm{~h}$ and then aged at $230{ }^{\circ} \mathrm{C}$ for $16 \mathrm{~h}$. The final thickness of the composites was about $3.4 \mathrm{~mm}$, giving fundamental thickness resonance frequency of $\leqslant 500 \mathrm{kHz}$.

The glass transition temperatures $T_{\mathrm{g}}$ of pure and glass sphere modified epoxies were determined using dynamic mechanical thermal analysis (DMTA) (defined as the maximum value of mechanical loss), using a dynamic mechanical analyser (DMA Q800, TA Instruments), on samples with dimensions of $25 \mathrm{~mm} \times 10 \mathrm{~mm} \times 4 \mathrm{~mm}$. Thermal expansion measurements were carried out in the temperature range $30-275^{\circ} \mathrm{C}$ using a dilatometer (DIL 402 $\mathrm{PC}, \mathrm{NETZSCH}$ ), on samples with dimensions of $25 \mathrm{~mm} \times$ $5 \mathrm{~mm} \times 5 \mathrm{~mm}$. The TEC, $\alpha$, was calculated according to

$$
\alpha_{T}=\frac{1}{L_{0}} \times \frac{\Delta L}{\Delta T},
$$

where $L_{0}$ is the specimen length at room temperature [23]. The densities of the pure and modified epoxies were measured by the Archimedes method. The longitudinal velocities of the epoxies were determined by the ultrasonic pulse-echo method using a $15 \mathrm{MHz}$ longitudinal wave transducer (Ultra Laboratory Inc.) The acoustic impedance $Z$ of the epoxies was then determined according to

$$
Z=\rho V_{\mathrm{L}},
$$

where $\rho$ is the density and $V_{\mathrm{L}}$ is the longitudinal wave velocity. The dielectric permittivity and loss as a function of temperature were determined from the capacitance and loss measured by an HP4284A LCR meter connected to a computer-controlled furnace, while the electromechanical coupling factor was determined by the resonance and anti-resonance frequencies measured using an HP4194 impedance phase-gain analyser, according to the IEEE Standard [24].

\section{Results and discussion}

\subsection{Properties of pure and modified epoxies}

The properties of pure and modified epoxies were investigated. Figure 1 shows the temperature-dependent TEC for epoxies

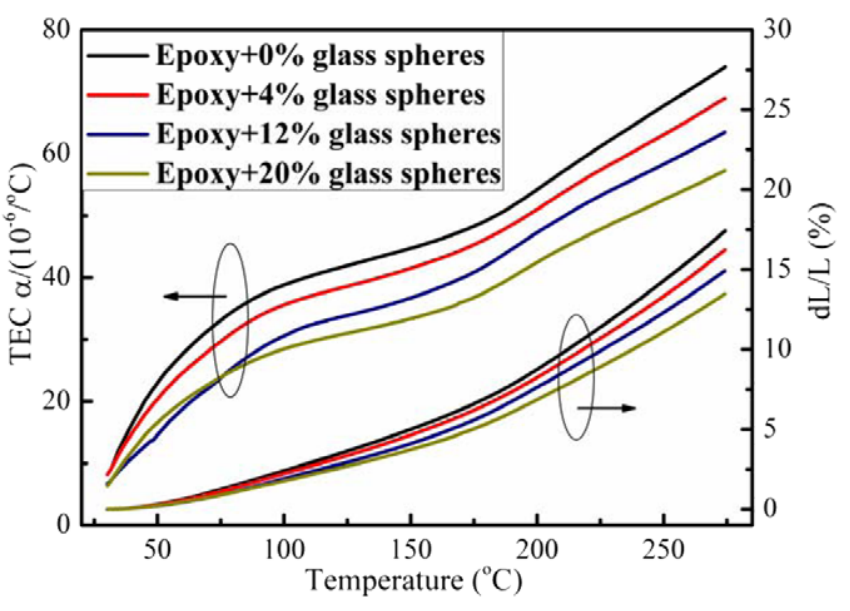

Figure 1. TEC as a function of temperature for pure and glass loaded epoxies. (Note that the left arrow illustrates TEC and the right arrow illustrates $\mathrm{d} L / L$.)

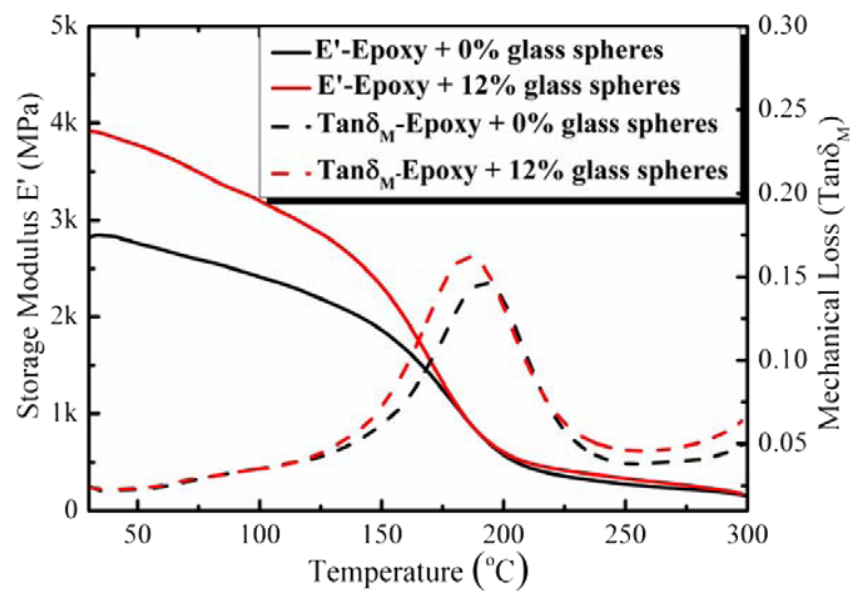

Figure 2. Temperature-dependent storage modulus and $\tan \delta_{\mathrm{M}}$ for pure and $12 \%$ glass modified epoxy.

modified with different volume ratios of glass spheres. It was found that TEC increased as a function of temperature for all the studied epoxies, but decreased with increasing glass sphere volume ratio, with values being on the order of $68 \mathrm{ppm}^{\circ} \mathrm{C}^{-1}$ and $59 \mathrm{ppm}^{\circ} \mathrm{C}^{-1}$ at $250{ }^{\circ} \mathrm{C}$ for pure and $12 \%$ glass loaded epoxies, respectively.

Figure 2 shows the temperature-dependent storage elastic moduli for the epoxy matrix with $0 \%$ and $12 \%$ glass spheres. It can be observed that the storage modulus $E^{\prime}$ for the epoxies decreased as temperature increasing and exhibited a sudden drop at about $190^{\circ} \mathrm{C}$, indicative of the softening of the epoxies. It should be noted that the incorporation of glass spheres increases the room temperature storage (elastic) modulus of the epoxy matrix, being $2800 \mathrm{MPa}$ for the pure epoxy and increased to $4000 \mathrm{MPa}$ for $12 \%$ glass sphere modified epoxy, without sacrificing the glass transition temperature $T_{\mathrm{g}}$ (peak point of damping-tan $\delta$ ). The temperature-dependent dielectric properties for the epoxies are given in figure 3. It was found that the dielectric permittivity and dielectric loss for all the epoxies increased at about $200^{\circ} \mathrm{C}$. Of particular interest is that the dielectric permittivity increased and the dielectric 


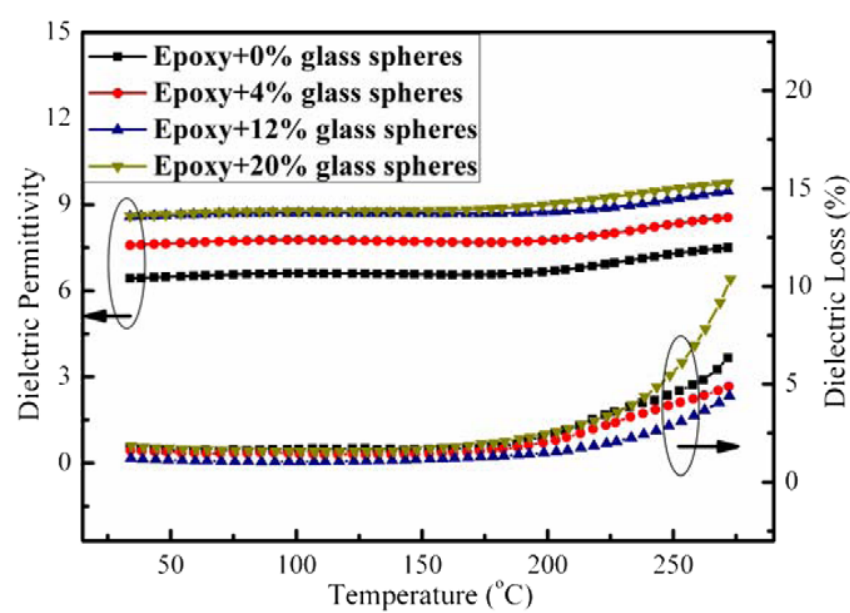

Figure 3. Temperature-dependent dielectric permittivity and loss measured at $10 \mathrm{kHz}$ for pure and glass loaded epoxies. (Note that the left arrow illustrate dielectric permittivity and the right arrow illustrate dielectric loss.)

Table 1. Material parameters for pure and glass sphere loaded epoxies.

\begin{tabular}{lllll}
\hline Parameter & $\begin{array}{l}\text { Epoxy } \\
(0 \%)^{\mathrm{a}}\end{array}$ & $\begin{array}{l}\text { Epoxy } \\
(4 \%)\end{array}$ & $\begin{array}{l}\text { Epoxy } \\
(12 \%)\end{array}$ & $\begin{array}{l}\text { Epoxy } \\
(20 \%)\end{array}$ \\
\hline$\rho\left(\mathrm{g} \mathrm{cm}^{-3}\right)$ & 1.85 & 1.93 & 2.17 & 2.03 \\
$\mathrm{Z}(\mathrm{Mrayl})$ & 4.8 & 5.1 & 6.4 & 5.5 \\
$T_{\mathrm{g}}\left({ }^{\circ} \mathrm{C}\right)^{\mathrm{b}}$ & 192 & 195 & 187 & 204 \\
$\mathrm{TEC}$ at $250^{\circ} \mathrm{C}\left(\mathrm{ppm}^{\circ} \mathrm{C}^{-1}\right)^{\mathrm{c}}$ & 68 & 63 & 59 & 52 \\
Dielectric loss at $250^{\circ} \mathrm{C}$ & $5 \%$ & $4 \%$ & $3 \%$ & $6 \%$ \\
$\begin{array}{l}\text { Dielectric permittivity } \\
\text { at } 250^{\circ} \mathrm{C}\end{array}$ & 7 & 8 & 9 & 9 \\
\end{tabular}

${ }^{a}$ Epoxy ( $x \%$ ) means epoxy with $x$ vol\% glass spheres.

${ }^{\mathrm{b}} T_{\mathrm{g}}$ is the glass transition temperature.

${ }^{c}$ TEC is the thermal expansion coefficient.

loss decreased, as glass spheres volume ratio increased from $0 \%$ to $12 \%$.

Table 1 summarizes the properties of the pure and modified epoxies. The density and the acoustic impedance of the epoxies were found to increase with glass sphere volume ratio increased from $0 \%$ to $12 \%$, above which, the acoustic impedance decreased, due to the fact that the viscosity of the epoxy was too high with $20 \%$ glass spheres, leading to the air bubbles in the epoxy $[25,26]$. Cracking and debonding may happen in the composites with excessive bubbles when the temperature increased due to the internal stress induced by different TEC of epoxy and air bubbles. This may lead to structural failure of the 1-3 composites and affect the thermal stabilities of the composites. This problem would be much more severe when the air bubbles are at the interface of ceramic rod/epoxy. It should be noted that the glass transition temperatures were similar, being on the order of $192-204{ }^{\circ} \mathrm{C}$, regardless of the glass sphere loading.

\subsection{Properties of monolithic PZT ceramics}

Prior to the fabrication of high-temperature 1-3 composites, the properties of high $T_{\mathrm{c}}$ monolithic PZT ceramics (TRS203) were measured and compared with PZT5A (TRS200).

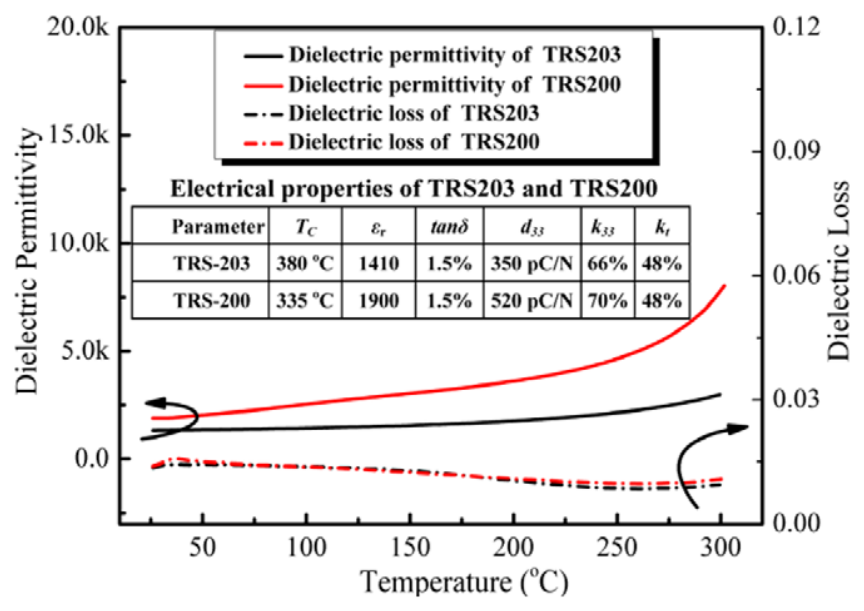

Figure 4. Dielectric permittivity and loss as a function of temperature for TRS203 and TRS200. (Note that the left arrow illustrates dielectric permittivity and right arrow illustrates dielectric loss.)

Figure 4 shows the temperature dependence of dielectric permittivity and loss of TRS203 and TRS200 (measured at $1 \mathrm{kHz}$ ), the room temperature properties were given in the small inset table. The dielectric losses of both ceramics were found to be $<2 \%\left(25^{\circ} \mathrm{C}-300^{\circ} \mathrm{C}\right)$. The temperature coefficient of dielectric permittivity of TRS203 was found to be $0.46 \%{ }^{\circ} \mathrm{C}^{-1}$ in the temperature range $25^{\circ} \mathrm{C}-300{ }^{\circ} \mathrm{C}$, being much lower than that of TRS200 $\left(1.2 \%{ }^{\circ} \mathrm{C}^{-1}\right)$, demonstrating improved temperature stability. It was found that TRS200 exhibited higher $d_{33}$ and $k_{33}\left(d_{33}=520 \mathrm{pC} \mathrm{N}^{-1}, k_{33}=70 \%\right)$ compared with TRS203 $\left(d_{33}=350 \mathrm{pC} \mathrm{N}^{-1}, k_{33}=66 \%\right)$; however, the $T_{\mathrm{c}}$ of $\mathrm{TRS} 203\left(380^{\circ} \mathrm{C}\right)$ was much higher than that of TRS200 $\left(335^{\circ} \mathrm{C}\right)$. Figure 5 shows the temperature dependence of the electromechanical coupling factor $k_{33}$ for high $T_{\mathrm{c}}$ PZT (TRS203) and compared with TRS200. Of particular significance is that the coupling factor $k_{33}$ of TRS203 maintain the same value from room temperature to $300^{\circ} \mathrm{C}$, indicating that TRS203 exhibited high thermal stability with broadened temperature usage range up to $300^{\circ} \mathrm{C}$.

\subsection{Thermal stability and reliability of 1-3 composites}

In this section, the room temperature properties, thermal stability and reliability of 1-3 composites were evaluated. The room temperature properties of 1-3 composites are summarized in table 2 . The measured piezoelectric coefficients $d_{33}$ were found to be on the order of $310 \mathrm{pC} \mathrm{N}^{-1}$, slightly lower than that of monolithic PZT ceramic $\left(\sim 350 \mathrm{pC} \mathrm{N}^{-1}\right)$, while the calculated electromechanical coupling factors $k_{t}$ were found to be $57 \%$, higher than the thickness coupling of monolithic ceramics $(\sim 48 \%)$. The acoustic impedance and mechanical quality factors $Q_{\mathrm{m}}$ of the composites were found to be on the order of 20-22 Mrayl and $<50$, respectively, lower than those values of PZT ceramic (30 Mrayl and $\sim 80$ ), which will benefit the high sensitivity and broad bandwidth transducer applications.

The thermal stability and reliability of PZT $(0 \% \& 12 \%)$ composites were evaluated by ageing the composites at $250{ }^{\circ} \mathrm{C}$ up to $200 \mathrm{~h}$ and $500 \mathrm{~h}$, respectively. The dielectric behaviour 


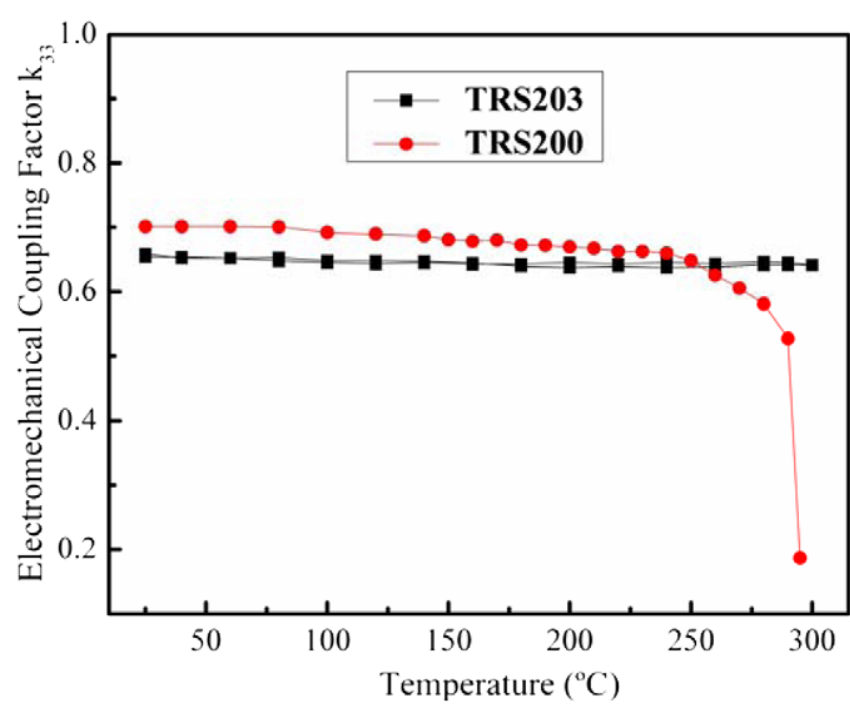

Figure 5. Electromechanical coupling factor $k_{33}$ as a function of temperature for TRS203 and TRS200.

Table 2. Electrical properties of high-temperature 1-3 composites.

\begin{tabular}{lllll}
\hline Parameter & $\begin{array}{l}\text { PZT } \\
(0 \%)^{\mathrm{a}}\end{array}$ & $\begin{array}{l}\text { PZT } \\
(4 \%)\end{array}$ & $\begin{array}{l}\text { PZT } \\
(12 \%)\end{array}$ & $\begin{array}{l}\text { PZT } \\
(20 \%)\end{array}$ \\
\hline Dielectric permittivity & 900 & 900 & 940 & 950 \\
Dielectric loss & $1.0 \%$ & $1.0 \%$ & $1.0 \%$ & $1.0 \%$ \\
$d_{33}\left(\mathrm{pC} \mathrm{N}^{-1}\right)$ & 310 & 310 & 310 & 310 \\
$k_{t}\left(\mathrm{k}_{33}\right)$ & $57 \%$ & $57 \%$ & $57 \%$ & $57 \%$ \\
$\mathrm{Z}(\mathrm{Mrayl})$ & 20 & 20 & 21 & 22 \\
$Q_{\mathrm{m}}^{b}$ at RT & 45 & 45 & 50 & 50 \\
$Q_{\mathrm{m}}$ at $250{ }^{\circ} \mathrm{C}$ & 30 & 30 & 25 & 25 \\
\hline
\end{tabular}

a PZT ( $x \%)$ means epoxy with $x$ vol\% glass spheres.

${ }^{\mathrm{b}} Q_{\mathrm{m}}$ is the mechanical quality factor.

as a function of temperature and ageing time for PZT $(0 \%)$ and PZT (12\%) composites are given in figures $6(a)$ and $(b)$, respectively, with the electromechanical coupling factor shown in the small insets. The dielectric permittivity for PZT $(0 \%)$ was found to be 900 at RT, increasing to 1520 at $250{ }^{\circ} \mathrm{C}$, while the corresponding dielectric loss was found to be $1.5 \%$ at RT, increased to $5 \%$ at $250{ }^{\circ} \mathrm{C}$. The electromechanical coupling factor was found to be $57 \%$ at RT, slightly increasing to $60 \%$ at $250{ }^{\circ} \mathrm{C}$, with minimal variation. Similar dielectric and electromechanical behaviours were also observed for PZT $(12 \%)$, as shown in figure $6(b)$.

However, obvious cracks were observed in the unmodified epoxy after ageing for $200 \mathrm{~h}$, as shown in figure 7 , leading to the damage of electrodes on PZT $(0 \%)$ composite. The piezoelectric coefficient $d_{33}$ and electromechanical coupling $k_{t}$ were found to be $170 \mathrm{pC} \mathrm{N}^{-1}$ and $43 \%$, respectively, indicating the failure of PZT $(0 \%)$ composites. In order to delineate the degradation mechanism, the surface of the PZT $(0 \%)$ composites was polished and re-electroded. It was found that both dielectric and electromechanical properties followed the same trend as the virgin sample, indicating that the property degradation of PZT $(0 \%)$ was attributed to the structural failure instead of the depolarization of the PZT ceramic, which may be caused by the internal stress induced by the different TECs of PZT $\left(\alpha \sim 2 \mathrm{ppm}^{\circ} \mathrm{C}^{-1}\right.$ at $250^{\circ} \mathrm{C}$ ) and the pure epoxy $\left(\alpha=68 \mathrm{ppm}^{\circ} \mathrm{C}^{-1}\right.$ at $250{ }^{\circ} \mathrm{C}$ ) [27].
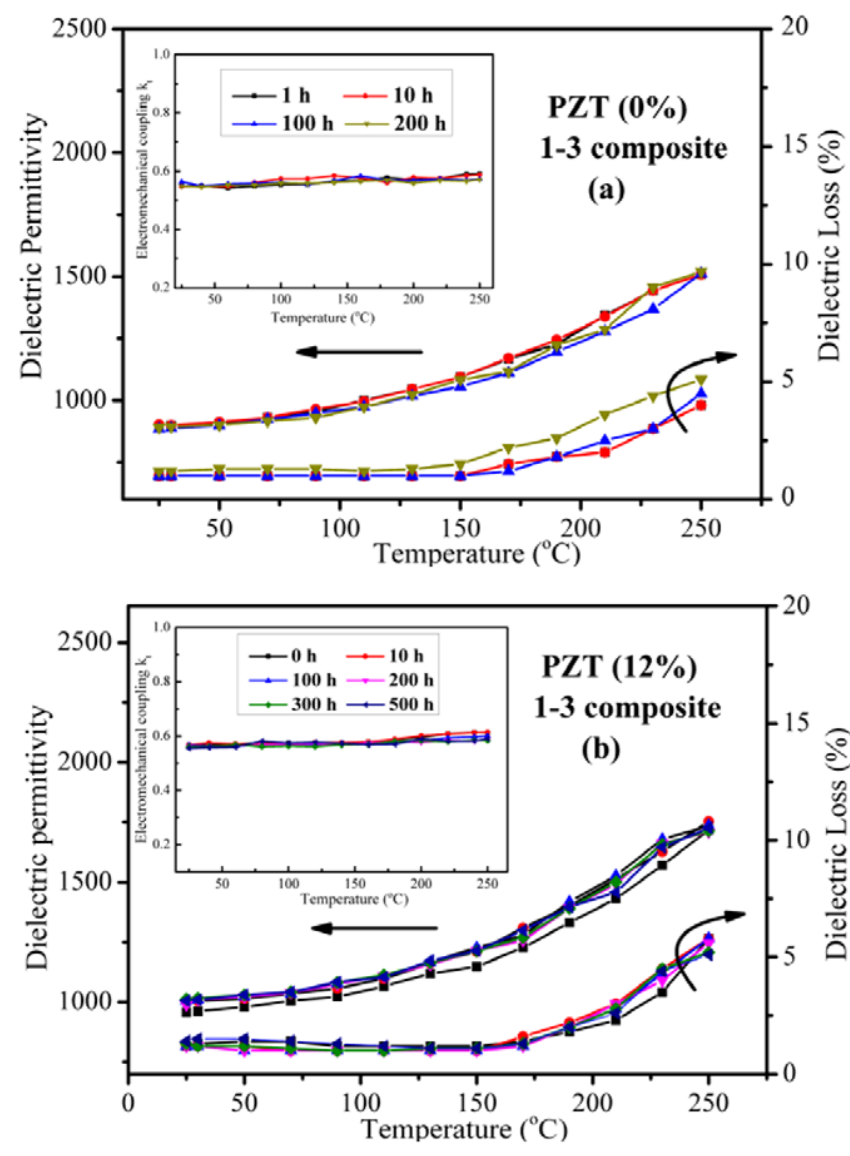

Figure 6. Temperature-dependent electrical properties for 1-3 composites ageing at $250^{\circ} \mathrm{C}$ for various times (a) PZT (0\%) 1-3 composite and (b) PZT (12\%) 1-3 composite. (Note that the left arrows illustrate dielectric permittivity and the left arrows illustrate dielectric loss.)

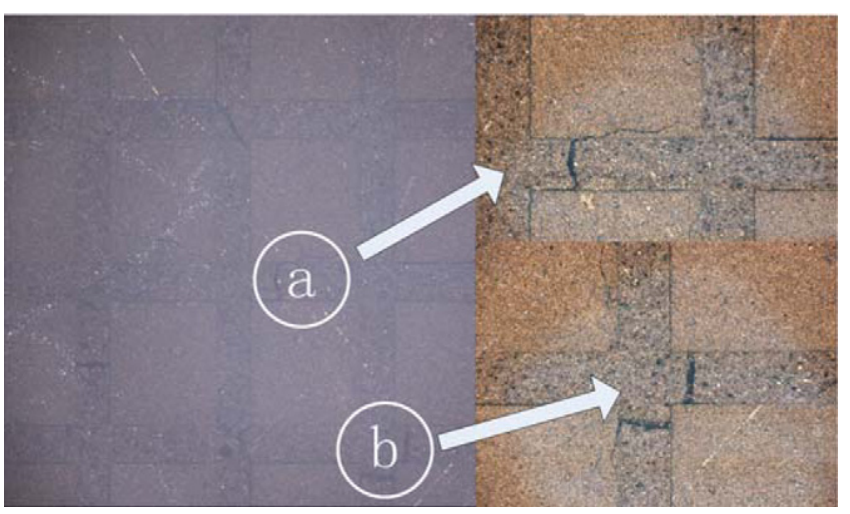

Figure 7. Photos of PZT (0\%) composite after ageing for $200 \mathrm{~h}$.

In contrast to PZT $(0 \%)$ composite, PZT (12\%) composite exhibited improved thermal reliability when aged at $250^{\circ} \mathrm{C}$. As shown in figure $6(b)$, no obvious variation in the dielectric permittivity, dielectric loss and electromechanical coupling were observed with ageing times up to $500 \mathrm{~h}$. The dielectric permittivity of PZT (12\%) composite was found to be 1010 after ageing for $500 \mathrm{~h}$, slightly higher than the value before ageing $\left(\varepsilon_{\mathrm{r}}=950\right)$, while the dielectric loss, piezoelectric coefficient $d_{33}$ and electromechanical coupling $k_{t}$ were found to maintain the same value of $1.5 \%, 300 \mathrm{pC} \mathrm{N}^{-1}$ and $56 \%$, 

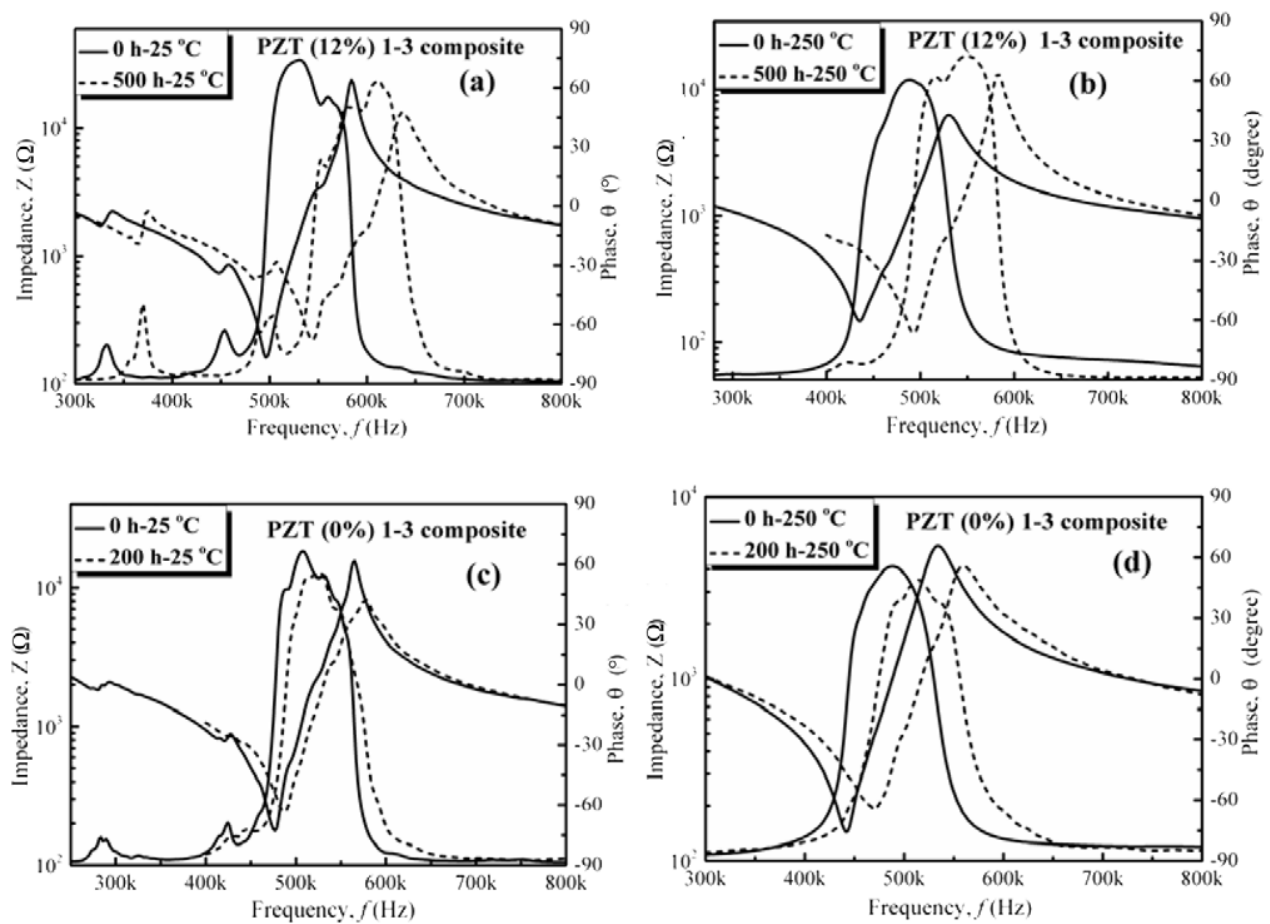

Figure 8. Measured electrical impedance and phase before and after ageing for 1-3 composites: (a) PZT (12\%) composite at RT, (b) PZT $(12 \%)$ composite at $250{ }^{\circ} \mathrm{C},(c)$ PZT $(0 \%)$ composite at RT and $(d)$ PZT $(0 \%)$ composite at $250{ }^{\circ} \mathrm{C}$. (Note that after ageing for $200 \mathrm{~h}$, the electrode of PZT $(0 \%)$ composites was damaged, which was removed and re-electroded. The impedance and phase spectrum of PZT $(0 \%)$ composite after $200 \mathrm{~h}$ were measured after re-electrode, as given in $(d)$.)

respectively. Of particular significance is that no structural failure was observed with high-temperature ageing. This improved thermal reliability was attributed to the low TEC (at $\left.250{ }^{\circ} \mathrm{C}\right)$ of epoxy $(12 \%)\left(\alpha=59 \mathrm{ppm}^{\circ} \mathrm{C}^{-1}\right)$ compared with the pure epoxy $\left(\alpha=68 \mathrm{ppm}^{\circ} \mathrm{C}^{-1}\right)$.

Figure 8 shows the electrical impedance and phase angle of PZT ( $0 \%$ and $12 \%$ ) composites before and after ageing. As shown in figures $8(a)$ and $(b)$, relatively high phase angle $\left(70^{\circ}\right.$ at $\left.250^{\circ} \mathrm{C}\right)$ was observed after ageing for $500 \mathrm{~h}$, indicative of a low damping (low loss) of PZT (12\%) composite, demonstrating minimal property degradation. However, for PZT $(0 \%)$ composite, low phase angle $\left(47^{\circ}\right.$ at $\left.250^{\circ} \mathrm{C}\right)$ was observed, as shown in figures $8(c)$ and $(d)$. The resonance and anti-resonance frequencies of both 1-3 composites were found to shift to higher frequencies after ageing, revealing the increasing of the effective velocities induced by the hardening of the polymer after ageing. It was observed from figure 8 that for both composites, the thickness coupling factors increased (from $57 \%$ to $60 \%$ ) but the mechanical quality factor $Q_{\mathrm{m}}$ decreased (from 45 to 30 for PZT- $0 \%$ and 50 to 25 for PZT$12 \%$ composites), as the temperature increased to $250^{\circ} \mathrm{C}$. This is due to the fact that as the temperature increased, the polymer became softer and the thickness mode became pure due to the less clamping from the soft polymer, which resulted in the enhancement of $k_{t}$. On the other hand, as the temperature increased, the electrical impedance at resonance frequency increased, while the magnitude of the electrical impedance at anti-resonance frequency decreased, indicated the increased damping and mechanical loss. And the increased mechanical loss leads to decrease in mechanical quality factor $Q_{\mathrm{m}}$.

\section{Conclusion}

In conclusion, the thermal stabilities and reliability of high-temperature 1-3 piezoelectric composites were studied. Temperature-dependent dielectric and electromechanical properties of the composites were measured after ageing at $250{ }^{\circ} \mathrm{C}$ with various dwelling times. The reliability of the composites was improved using glass sphere modified epoxy fillers, which has lower thermal expansion coefficient. Obvious cracks were observed and the electrodes were damaged in PZT $(0 \%)$ composite after ageing for $200 \mathrm{~h}$, leading to the structural failure. In contrast, neither electrical properties variation nor structural failure was observed for PZT (12\%) composite after ageing at $250^{\circ} \mathrm{C}$ up to $500 \mathrm{~h}$, due to the decreased thermal expansion of the modified filler, making it a potential candidate for NDE type transducer applications at elevated temperature.

\section{Acknowledgments}

The research was supported in part by the NIH under Grant No 2P41EB002182-15A1.O. One of the authors ( $\mathrm{L} \mathrm{L} \mathrm{Li)}$ wants to acknowledge the support from China Scholarship Council. Raffi Sahul from TRS Technologies is acknowledged for offering PZT ceramics.

\section{References}

[1] McNab A, Kirk K J and Cochran A 1998 Ultrasonic transducers for high temperature applications IEE Proc. Sci. Meas. Technol. 145 229-36 
[2] Kazys R, Volesis A, Sliteris R, Mazeika L, Nieuwenhove R V, Kupschus P and Abderrahim H A 2005 High temperature ultrasonic transducers for imaging and measurements in a liquid $\mathrm{Pb} / \mathrm{Bi}$ eutectic alloyIEEE Trans. Ultrason. Ferroelect. Freq. Control 52 525-37

[3] Kirk K J, Lee C K and Cochran S 2005 Ultrasonic thin film transducers for high-temperature NDT Insight 47 85-7

[4] Williams J H and Johnson C D 2004 Acoustic and optical borehole-wall imaging for fractured-rock aquifer studies J. Appl. Geophys. 55 151-9

[5] Kirschman R K 1999 High-Temperature Electronics (Piscataway, NJ: IEEE Press)

[6] Veneruso T 1991 Proc. 1st Int. High Temperature Electronics Conf. (Albuqueruqe, NM)

[7] Cegla F B, Cawley P, Allin J and Davies J 2011 High-temperature $\left(>500^{\circ} \mathrm{C}\right)$ wall thickness monitoring using dry-coupled ultrasonic waveguide transducers IEEE Trans. Ultrason. Ferroelect. Freq. Control 58 156-67

[8] Newnham R E, Bowen L J, Klicker K A and Cross L E 1980 Composite piezoelectric transducers Mater. Eng. 293-106

[9] Shaulov A A, Smith W A and Singer B M 1984 Performance of ultrasonic transducers made from composite piezoelectric materials IEEE Ultrasonic Symp. (Dallas, TX) pp 545-8

[10] Smith W A and Shaulov A A 1985 Tailoring the properties of composite piezoelectric materials for medical ultrasonic transducers IEEE Ultrasonic Symp. (San Francisco, CA) pp 642-7

[11] Benjamin K C and Petrie S 2001 Design, fabrication, and measured acoustic performance of a 1-3 Piezoelectric composite Navy calibration standard transducer J. Acoust. Soc. Am. 109 1973-8

[12] Xue Q, Stanton M and Elfbaum G 2003 A high temperature and broadband immersion 1-3 piezo-composite transducer for accurate inspection in harsh environments IEEE Ultrasonic Symp. (Honolulu, HI) pp 1372-5

[13] Richard C, Lee H S and Guyomar D 2004 Thermo-mechanical stress effect on 1-3 piezocomposite power transducer performance Ultrasonics 42 417-24

[14] Devallencourt C, Michau S, Bantignies C and Felix N 2004 A $5 \mathrm{MHz}$ piezocomposite ultrasound array for operations in high temperature and harsh environment IEEE Ultrasonic Symp. (Montreal) pp 1294-7

[15] Parr A C S, O’Leary R L, Hayward G, Smillie G, Benny G, Ewing H and Mackintosh A R 2002 Investigating the thermal stability of 1-3 piezoelectric composite transducers by varying the thermal conductivity and glass transition temperature of the polymeric filler material IEEE Ultrasonic Symp. (Munich) pp 1173-6

[16] Parr A C S, O'Leary R L and Hayward G 2005 Improving the thermal stability of 1-3 piezoelectric composite transducers IEEE Trans. Ultrason. Ferroelect. Freq. Control 52 550-63

[17] Shepherd G, Cochran A, Kirk K J and McNab A 2002 1-3 connectivity composite material made from lithium niobate and cement for ultrasonic condition monitoring at elevated temperatures Ultrasonics 40 223-6

[18] Schmarje N, Kirk K J and Cochran S 2007 1-3 connectivity lithium niobate composites for high temperature operation Ultrasonics 47 15-22

[19] Schmarje N, Kirk K J and Cochran S 2005 Comparison of $y / 36^{\circ}$-cut and $z$-cut lithium niobate composites for high temperature ultrasonic applications Nondestr. Test. Eval. 20 77-87

[20] Huang C J, Fu S Y, Zhang Y H, Lauke B, Li L F and Ye L 2005 Cryogenic properties of $\mathrm{SiO}_{2}$ /epoxy nanocomposites Cryogenics 45 450-4

[21] Kang S, Hong S I, Choe C R, Park M, Rim S and Kim J 2001 Preparation and characterization of epoxy composites filled with functionalized nanosilica particles obtained via sol-gel process Polymer 42 879-87

[22] Savakus H P, klicker K A and Newnham R E 1981 PZT-epoxy piezoelectric transducers: a simplified fabrication procedure Mater. Res. Bull.16 677-80

[23] Gladysz G M and Chawla K K 2001 Coefficients of thermal expansion of some laminated ceramic composites Compos. A-Appl. S. 32 173-8

[24] ANSI/IEEE Standard 1987 IEEE Standard on Piezoelectricity (New York, NY: ANSI/IEEE Standard)

[25] Frigione M, Caló E, Maffezzoli A, Acierno D, Carfagna C and Ambrogi V 2006 Performance microspherical inclusions for rheological control and physical property modification of epoxy resins J. Appl. Polym. Sci. $100748-57$

[26] $\mathrm{Ku} \mathrm{H}$ and Wong P 2012 Contrast on tensile and flexural properties of glass powder reinforced epoxy composites: pilot study J. Appl. Polym. Sci. 123 152-61

[27] Kallaev S N, Gadzhiev G G, Kamilov I K, Omarov Z M, Sadykov S A and Reznichenko L A 2006 Thermal properties of PZT-based ferroelectric ceramics Phys. Solid State 48 1169-70 